\title{
Relationship between fasting blood glucose and body mass index among students of a medical college
}

Vargese $\mathrm{SS}^{1 *}$, Joseph $\mathrm{TM}^{2}$, Mathew $\mathrm{E}^{3}$

*Corresponding author:

${ }^{1}$ Dr. Saritha Susan Vargese, MBBS MD, Assistant Professor, Department of Community Medicine, Pushpagiri Institute of Medical Sciences and Research centre, Tiruvalla.

Email: saritha.vargese@gmail.com ㅅCID

${ }^{2}$ Department of Community medicine Sree Narayana Institute of medical Sciences, Ernakulam.

${ }^{3}$ Assistant Professor, Department of Community Medicine, Pushpagiri Institute of Medical Sciences and Research Centre, Tiruvalla,

Received: Jan. 17, 2019

Accepted: Feb. 20, 2019

Published online: Dec. 27, 2019

Information about the article:

Received: Jan. 17, 2019

Accepted: Feb. 20, 2019

Published online: Dec. 27, 2019

Publisher

Nepal Health Research Society, Bahundhara -6, Gokarnesowor Municipality, Kathmandu, Nepal

eISSN 2382-5545, ISSN 2676-1343 (Print)

(C) The Author(s). 2019

Content licensing: CC BY 4.0

\begin{abstract}
Background

Obesity is one of the most important modifiable risk factors in the pathogenesis of lifestyle diseases like atherosclerosis, hypertension and type 2 diabetes mellitus. Overweight or obese adolescents are at an increased risk of developing diabetes and hypertension in future. A study was done to determine the relationship between body mass index and fasting blood glucose among students of a tertiary care teaching hospital.
\end{abstract}

\section{Materials and methods}

A cross sectional analytical study was carried out among all medical students in a tertiary care teaching hospital in Kerala who consented to participate after obtaining approval from Institutional Research and Ethics Committee. The study tools used were standardized weighing machine, stadiometer, Accu-check glucometer and strips, disposable needles and pre-designed questionnaire.

\section{Results}

Among the 254 study participants, $67 \%$ were females. The prevalence of impaired fasting glucose is $18.11 \%$ in the study population. No significant correlation was found between fasting blood glucose and body mass index. There was an increase in median FBS as the BMI increases, though not statistically significant $(p=0.08)$. In the linear regression model, the statistic R2 explains that $7.9 \%$ of the variability in fasting blood glucose is explained by body mass index.

\section{Conclusion}

The prevalence of prediabetes among the study participants was very high and it was higher among those who were overweight. The need of the hour is to identify the high-risk group in the community right from the young age and initiate trials or intervention studies to prevent or delay the onset of diabetes.

Key words

Body mass index, correlation, fasting blood glucose, medical students 